\title{
Clinical Patterns of Diffuse Parenchymal Lung Disease in Kuwait: A Prospective Study
}

\author{
A. Abula B.O. Onadeko ${ }^{a}$ M.E. Khadadah ${ }^{a}$ N. Behbehani ${ }^{a}$ M. Cerna ${ }^{b}$ \\ J.M. Cherian ${ }^{c}$ N. Maradnid $\quad$ B. Jayakrishnan ${ }^{b}$ \\ aDepartment of Medicine, Faculty of Medicine, Kuwait University, ${ }^{\mathrm{b}}$ Respiratory Unit, Al-Rashid Allergy Center, \\ 'Department of Radiology, Al-Sabah Hospital, and d Respiratory Unit, Mubarak Al-Kabeer Hospital, Kuwait
}

\section{Key Words}

Pulmonary fibrosis - Pulmonary function test - Cigarette smoking $\cdot$ High resolution computed tomography · Lung biopsy

\begin{abstract}
Objective: To report our experience of the clinicopathological patterns of diffuse parenchymal lung disease (DPLD). Subjects and Methods: Over a 4-year period, 75 patients (41 males, 34 females), aged $13-76$ years, who were referred to Mubarak Al-Kabeer and the Chest Diseases Hospitals, Kuwait with a diagnosis of diffuse lung disease, were included in the study. After a comprehensive history and physical examination, further investigations were done, including hematological and immunological profiles, sputum and bronchoalveolar lavage fluid examination, chest radiograph, high resolution computed tomography (HRCT), pulmonary function test and lung biopsy. Results: Of the 75 patients 60 (80\%) were over 40 years of age. The duration of symptoms in 34 patients (45\%) was less than 6 months and longer than 1 year in $28(37.7 \%)$ patients. Twenty-five of the patients were cigarette smokers. The mean forced lung
\end{abstract}

capacity (FVC), total lung capacity and diffusing capacity for carbon monoxide were less than $60 \%$ of the predicted values in most patients. There was a significant difference in mean FVC value between smokers and nonsmokers $(p<0.05)$. The HRCT findings were at an advanced stage in 65 patients, with additional honeycombing in 21 of the 65 patients. Idiopathic pulmonary fibrosis was the most common cause of DPLD, occurring in 52 patients, followed by sarcoidosis and collagen vascular diseases. Conclusion: DPLD was observed predominantly in middle aged and elderly patients, due probably to increasing industrialization in the country. The role of cigarette smoking as a contributory factor remains unclear.

Copyright $@ 2004$ S. Karger AG, Basel

\section{Introduction}

Many acute and chronic lung diseases of varying degrees of inflammation and fibrosis are collectively referred to as diffuse parenchymal lung disease (DPLD) or interstitial lung disease [1]. The etiology of many of these diseases remains unknown. However, since Hamman and Rich [2] described the clinical and morphologic features

\section{KARGER}

Fax +41613061234

E-Mail karger@karger.ch

www. karger.com
(C) 2004 S. Karger AG, Basel

1011-7571/04/0132-0078\$21.00/0

Accessible online at:

www. karger.com/mpp
Prof. B.O. Onadeko

Department of Medicine

Kuwait University, PO Box 24923

13110 Safat (Kuwait)

Tel. +965 5319596, Fax +965 5338907, E-Mail onadeko@hsc.kuniv.edu.kw 
of 4 patients with progressive rapidly fatal diffuse pulmonary fibrosis, progress has been made in elucidating the clinicopathologic features of these diseases [1, 3-11].

A common pathologic feature, which is injury to the alveolar wall leading to the development of alveolitis with a subsequent loss of alveolar gas exchange, is found in many of these patients. Patients with these conditions present as a diagnostic and therapeutic challenge, the response to treatment being variable.

In the last three decades, Kuwait, an Arabian Gulf country, has witnessed an economic boom, leading to increased industrialization and an influx of migrant workers from neighboring countries, with attendant introduction of various health problems, among which has been the emergence of DPLD. However, since the only documented report on interstitial lung disease in Kuwait is limited to high resolution computed tomographic (HRCT) changes [12], documentation of the incidence, clinical characteristics and patterns of this cluster of lung diseases is of great importance. In this study, we report our experience on the clinicopathologic patterns of DPLD in Kuwait.

\section{Subjects and Methods}

This 4-year prospective collaborative, multidisciplinary study was carried out at two tertiary care hospitals (Mubarak Al-Kabeer and The Chest Diseases Hospitals) in Kuwait, between January 1997 and December 2000. Of the 75 patients, 41 were males and 34 females; mean age $51.1 \pm 14.18$ and median 52 years. Forty (53\%) were Kuwaiti nationals, while the remaining 31 (47\%) were nonKuwaitis.

All the patients were referred from other hospitals and polyclinics either because of abnormal diffuse chest radiographic pattern or symptoms of progressive shortness of breath with abnormal radiographic features.

The inclusion of patients as DPLD was based on criteria adopted by Cushley et al. [8] and Raghu et al. [10]. After a comprehensive history and physical examination, all patients were subjected to investigations that included complete blood count, erythrocyte sedimentation rate, and full immunological profile, i.e. rheumatoid factor, antinuclear antibodies, anti-double-stranded DNA, complements, C-reactive protein, cytoplasmic and perinuclear antinuclear cytoplasmic antibodies, serum immunoglobulins, and precipitating antibodies to aspergillus and other specific antigens. A chest radiograph, followed by HRCT, was done routinely on all patients. The HRCT scans were interpreted by 2 radiologists, whose findings were based on consensus. Pulmonary function tests and arterial blood gases were carried out on the patients when feasible.

Bronchoscopy and transbronchial biopsy were performed on 33 patients. At least five pieces of lung tissue were sent for each biopsy to ensure that adequate tissue sample was available for processing and interpretation. Open lung biopsy was performed on 13 patients when considered necessary to reach a diagnosis if the transbronchial biopsy report was inconclusive or not diagnostic. The open lung biopsy was carried out by the same thoracic surgeon in all cases while the lung histopathology was reported by 2 experienced pathologists.

Other relevant diagnostic investigations were done when indicated, including examination of sputum for acid-fast bacilli by direct smear and culture. Sputum was also examined cytologically (for malignant cells). Examination of bronchoalveolar lavage fluid for microorganisms, acid-fast bacilli and malignant cells was done.

\section{Diagnosis}

Using criteria adopted by Cushley et al. [8], a diagnosis of each DPLD was made as follows: (a) idiopathic pulmonary fibrosis (IPF): based on the presence of bilateral inspiratory crackles (with or without digital clubbing), HRCT, and histopathological findings [11]; (b) sarcoidosis: based on clinical features and lung tissue biopsy; (c) bronchiolitis obliterans organizing pneumonia (BOOP): based on criteria published by Epler et al. [13] and Colby [14], which include clinical features, evidence of pulmonary infiltrates on chest radiograph, HRCT findings, open lung biopsy and response to corticosteroids; (d) collagen vascular diseases: based on clinical features and relevant serological tests and tissue biopsy; (e) extrinsic allergic alveolitis/hypersensitivity pneumonitis: based on clinical features, relevant serological tests, tissue biopsy, and response to therapy; (f) Wegener's granulomatosis: based on clinical and radiographic features, combined with relevant serological test and tissue biopsy; (g) miliary tuberculosis: based on tissue biopsy, with characteristic histological features of caseating granuloma. The final diagnosis in each patient was reviewed by at least 2 pulmonologists.

\section{Treatment}

When the cause of DPLD was known, specific treatment was given. Patients with IPF who presented with symptoms/worsening of symptoms, coupled with significant restriction of pulmonary function tests and/or HRCT abnormalities, were given prednisolone alone in doses ranging from 30 to $40 \mathrm{mg} /$ day for 8 weeks, with the dose tapering gradually to $10 \mathrm{mg} /$ day. Azathioprine $100-200 \mathrm{mg}$ was added to prednisolone in patients who did not improve either at 3 or 6 months.

In the case of sarcoidosis, treatment involved prednisolone in doses of $1 \mathrm{mg} / \mathrm{kg}$ body weight per day, which was subsequently tapered based on clinical response. Prednisolone therapy was also given to patients diagnosed with BOOP or extrinsic allergic alveolitis. Patients with Wegener's granulomatosis were treated with prednisolone and cyclophosphamide, and antituberculosis drugs were given to patients with miliary tuberculosis.

\section{Follow-Up}

All of the 75 patients were followed up every 3 months for 1 year. Their symptoms, pulmonary function tests, and when indicated, chest radiograph, were reviewed at each visit in the outpatient department.

\section{Results}

A summary of age distribution, symptoms, signs and radiographic investigations at presentation is given in table 1 . Most of the patients $(79.8 \%)$ were age 40 years 
and over. The most common symptom was progressive shortness of breath, occurring in $93 \%$ of cases. Digital clubbing, associated with IPF, was observed in $75 \%$ of the cases. Ninety-three percent of the subjects had crackles, found mostly in the mid and late inspiratory phase of the respiratory circle (late inspiratory crackles were observed mainly in patients with IPF). Of the 75 patients, 34 (45\%) had symptoms of less than 6 months in duration, while 28 $(16 \%)$ had symptoms for over a year before presentation; $34 \%$ were cigarette smokers. IPF was the most common DLPD, occurring in $69 \%$ of the cases, followed by sarcoidosis, collagen vascular disease, BOOP and extrinsic allergic alveolitis (table 2).

\section{Pulmonary Function Tests}

Pulmonary function tests were restrictive in pattern in $87 \%$ of the subjects, while mixed restrictive and obstructive pattern was observed in the remaining $13 \%$ of the patients, mostly with rheumatoid lung disease and other connective tissue diseases. All the subjects diagnosed with IPF had restrictive lung pattern. The mean pulmonary function test parameters in patients with IPF are shown in table 3. A significant difference was also observed in the mean FVC value between smokers and nonsmokers $(\mathrm{p}=$ 0.05 ). The mean oxygen saturation at rest was $90.0 \pm$ $7.17 \%$. Ten subjects had oxygen saturation below $90 \%$, while 4 subjects had below $80 \%$ at presentation.
Table 1. Summary of age distribution, symptoms, signs and radiographic investigations at presentation

\begin{tabular}{lcc}
\hline Variables & \multicolumn{2}{l}{ Cases } \\
\cline { 2 - 3 } & $\mathrm{n}$ & $\%$ \\
\hline Age-groups & & \\
$\quad<40$ & 15 & 20 \\
$\quad 40-60$ & 32 & 42.7 \\
$\quad>60$ & 28 & 37.1 \\
Breathlessness & 70 & 93.2 \\
History of smoking & & \\
$\quad$ Smokers & 26 & 34 \\
$\quad$ Never smokers & 49 & 66 \\
Digital clubbing & 37 & 75 \\
Crackles & 70 & 93.2 \\
Plain chest radiograph & 75 & 100 \\
HRCT scan & 65 & 87 \\
\end{tabular}

Table 2. Various patterns of DPLD

\begin{tabular}{lrr}
\hline \multirow{2}{*}{ Disease } & \multicolumn{2}{l}{ Cases } \\
\cline { 2 - 3 } & $\mathrm{n}$ & $\%$ \\
\hline IPF & 52 & 69.3 \\
Sarcoidosis & 6 & 8.0 \\
BOOP & 3 & 4.0 \\
Rheumatoid arthritis & 2 & 2.7 \\
Scleroderma & 2 & 2.7 \\
Extrinsic allergic alveolitis & 2 & 2.7 \\
Wegener's granulomatosis & 2 & 2.7 \\
Miliary tuberculosis & 2 & 2.7 \\
Other connective tissue diseases & 1 & 1.3 \\
Lupus pneumonitis & 1 & 1.3 \\
Pneumocystis carinii pneumonia & 1 & 1.3 \\
Myeloproliferative disease & 1 & 1.3 \\
\hline Total & 75 & 100 \\
\hline
\end{tabular}

Table 3. Mean pulmonary function test parameters in patients with IPF at presentation

\begin{tabular}{|c|c|c|c|c|c|c|c|c|c|c|}
\hline \multirow[t]{2}{*}{ Variables } & \multicolumn{3}{|c|}{ Cases } & \multicolumn{3}{|c|}{ Smokers } & \multicolumn{3}{|c|}{ Nonsmokers } & \multirow[t]{2}{*}{$\mathrm{p}$ value } \\
\hline & $\mathrm{n}$ & mean & SD & $\mathrm{n}$ & mean & SD & $\mathrm{n}$ & mean & $\mathrm{SD}$ & \\
\hline FVC, $\%$ predicted & 48 & 56.14 & 16.4 & 20 & 52.5 & 17.8 & 28 & 61.5 & 15.0 & 0.050 \\
\hline TLC, $\%$ predicted & 48 & 67.0 & 16.8 & 20 & 61.8 & 16.7 & 28 & 66.6 & 13.1 & 0.241 \\
\hline $\mathrm{RV}, \%$ predicted & 48 & 92.05 & 37.3 & 20 & 93.6 & 42.6 & 28 & 94.5 & 32.0 & 0.933 \\
\hline TLCO, $\%$ predicted & 48 & 57.60 & 20.7 & 20 & 51.97 & 12.0 & 28 & 57.6 & 22.1 & 0.280 \\
\hline$\% \mathrm{SO}_{2}$ & 34 & 90.58 & 7.73 & 15 & 90.9 & 7.17 & 19 & 90.27 & 8.3 & 0.503 \\
\hline
\end{tabular}

$\mathrm{FVC}=$ Forced vital capacity; TLC $=$ total lung capacity RV $=$ residual volume; TLCO $=$ diffusing capacity of carbon monoxide; $\mathrm{SO}_{2}=$ oxygen saturation. 


\section{Radiological Tests}

All the subjects had abnormal chest radiographs, mainly confluent reticular infiltrates or diffuse reticulonodular shadowing. Honeycomb features were reported in 18 $(24 \%)$ of cases. The HRCT findings indicated that many of the subjects presented at an advanced stage (table 4). In most cases, HCRT revealed more than one abnormality that included peripheral/subpleural infiltrates, centrilobular infiltrates, intralobular interstitial thickening and traction bronchiectasis. In 21 (32\%) of the cases, honeycomb appearance, in addition to other features, was recorded. HRCT findings suggestive of usual interstitial pneumonia, desquamative interstitial pneumonia (DIP) or nonspecific interstitial pneumonia were reported in patients with IPF.

An association was observed between these HRCT findings and similar histological subgroups in the tissue biopsy in some of the patients.

Table 4. Findings from $\mathrm{HRCT}^{1}$

\begin{tabular}{lll}
\hline HRCT findings & $\mathrm{n}$ & $\%$ \\
\hline Ground glass appearance & 35 & 53.8 \\
Peripheral/subpleural infiltrates & 40 & 61.5 \\
Centrilobular reticular infiltrates & 36 & 55.4 \\
Intralobular interstitial thickening & 40 & 61.5 \\
Traction bronchiectasis & 25 & 38.5 \\
Honeycomb abnormality & 21 & 32.3 \\
Peripheral/subpleural emphysema & 14 & 21.5 \\
\hline
\end{tabular}

1 Some cases had combined lesions.

\section{Response to Therapy}

The response to therapy was not satisfactory in $50 \%$ of the subjects with IPF. The mean values for forced vital capacity, total lung capacity and diffusing capacity of carbon monoxide were stable at 3 months, but at 12 months, $48 \%$ of the subjects did not report for reevaluation and as such were lost to follow-up. Among the remaining 53\% the pulmonary parameters had deteriorated in over 50\% of them at the end of the monitoring period (table 5). Four $(5 \%)$ died within in the 1-year period of follow-up.

However, $4(5 \%)$ patients with the histological features of DIP showed some satisfactory response to prednisolone; their forced vital capacity value had increased after 3 months of observation although no further improvement was seen. Two of the patients with DIP also had radiographic improvement at the end of the observation period. Subjects treated for sarcoidosis, BOOP and extrinsic allergic alveolitis showed improvement clinically and radiographically at the end of the observation period. Those treated for collagen vascular disease had symptomatic relief, although no significant change in their pulmonary function and radiographic patterns was observed. The subjects treated for tuberculosis showed clinical and radiographic improvement at the end of the therapy.

\section{Discussion}

The number of cases documented over the period of our study may not be a true reflection of the extent of the disorders in Kuwait because some of the patients could have been treated in other institutions.

DPLD, which may remain undetected and only diagnosed once it has become irreversible, is likely more prev-
Table 5. Pulmonary function parameters at (1) presentation and (2) after 3 months of treatment of patients with IPF

\begin{tabular}{llllllll}
\hline Variables & $\mathrm{n}$ & Mean & SD & \multicolumn{3}{l}{$95 \%$ CI of the difference } & \\
\cline { 5 - 8 } & & & & & lower & upper & p value \\
\hline FVC & 1 & & 56.14 & 16.4 & -2.9965 & 2.4765 & 0.848 \\
& 2 & 37 & 56.24 & 15.73 & & & \\
TLC & 1 & & 67.0 & 16.8 & -2.3463 & 2.2111 & 0.952 \\
& 2 & 37 & 64.18 & 15.3 & & & \\
TLCO & 1 & & 57.64 & 20.7 & -6.9718 & 3.7287 & 0.541 \\
& 2 & 37 & 57.24 & 17.54 & & & \\
\hline
\end{tabular}

For abbreviations, see table 3 . 
alent than generally thought. The number of different forms, estimated at about 130 in the eighties, is now on the rise due to increasing exposure to new hazardous agents in industry, environmental pollution or administration of new drugs [15-17].

Although this study did not investigate the risk factors associated with DPLD, smoking was investigated because of its high prevalence in Kuwait [18].

Furthermore, smoking has been implicated as one of the environmental risk factors triggering DPLD, especially the idiopathic type [19-21]. Nagai et al. [20] suggested that chronic smoking is deeply involved in the pathogenesis of this disease and that it may influence the clinical course in terms of either disease severity or progression. However, since only one third of the patients in this study admitted to ever smoking, it appears that cigarette smoking was not a risk factor. Equally important is the fact that the proportion of males to females was $54.7 \%$ males and $45.3 \%$ females, similar to findings reported in other studies $[22,23]$. The almost equal male-to-female ratio in all these studies is somewhat surprising since males habitually smoke more than females, thus de-emphasizing the impact of cigarette smoking on this disorder. Nevertheless, it remains possible that cigarette smoking may just be one of the risk factors involved in the pathogenesis of DPLD.

DPLD occurs predominantly in middle-aged and elderly patients $[23,24]$, consistent with our findings in which $80 \%$ of patients were over 40 years of age, with a mean of 52 years.

The most frequently encountered cause of DPLP was IPF (69\%), followed by sarcoidosis, collagen vascular disease, and BOOP, respectively. The sequence of these DPLD-associated diseases is similar to that reported previously: IPF [12, 21, 24, 25-29], sarcoidosis [22], collagen vascular disease [21], and BOOP [21]. Rheumatoid ar- thritis and scleroderma are the most frequently encountered collagen vascular diseases in Kuwait. Extrinsic allergic alveolitis was also encountered, although very few cases were found. Clinical history, indicating exposure to organic substances coupled with appropriate precipitating antibody test, and tissue lung biopsy and response to corticosteroid assist in confirming the diagnosis.

The predominance of IPF in this study cannot be satisfactorily explained. It has been well documented that HRCT has a high degree of accuracy in diagnosing many forms of DPLD [24, 26, 29]. Furthermore, it is unlikely that overdiagnosis could be a contributing factor as our diagnostic procedure involved extensive clinical investigation, HRCT findings, and confirmation by tissue biopsy (in many of the cases), in addition to the review of all cases by a minimum of 2 pulmonologists. Thus, the predominance of IPF in our study may be a true reflection of the high prevalence of this disorder in Kuwait.

\section{Conclusion}

DPLD was diagnosed mostly in subjects over 40 , and among the cluster of DPLD diseases, IPF was by far the most common. The role of cigarette smoking as a contributory factor remains obscure.

\section{Acknowledgments}

We are indebted to the attending physicians and residents in the two hospitals who referred patients to us for this study. We are grateful to the primary care physicians in the polyclinics who also sent patients for investigation. We thank the technicians in the pulmonary function laboratories of the hospitals involved in this study for their assistance. The statistical assistance of Dr. T.N. Sugathan is gratefully acknowledged.

\section{References}

1 Crystal RG, Bitterman PB, Rennard SI, Hance AJ, Keogh BA: Interstitial lung disease of unknown cause: Disorders characterized by chronic inflammation of the lower respiratory tract. N Engl J Med 1984;310:154-166.

2 Hamman L, Rich AR: Acute diffuse interstitial fibrosis of the lungs. Bull Johns Hopkins Hosp 1944;74:177-212

3 Felson B: A new look at pattern recognition of diffuse pulmonary disease. AJR Am J Roentgenol 1979;133:183-189.
4 Gaensler EA, Carrington CB: Open biopsy for chronic diffuse infiltrative lung disease: Clinical, roentgenographic, and physiological correlations in 502 patients. Ann Thorac Surg 1980; 30:411-420.

5 Hunninghake GW, Fauci AS: Pulmonary involvement in the collagen vascular disease. Am Rev Respir Dis 1979;119:471-503.

6 Kelley MA, Daniele RP: Exercise testing in interstitial lung disease. Clin Chest Med 1984; 5:145-156
7 Mortenson RL, Bogin RM, King TE: Interstitial lung diseases; in Stretton TB (ed): Recent Advances in Respiratory Medicine, ed 4. Edinburgh, Churchill Livingstone, 1992, pp 163182.

8 Cushley MJ, Davison AG, duBois RM, Egan J, Flower CD, Gibson GJ, Greening AP, Ibrahim NB, Johnston JD, Mitchell DM, et al: The diagnosis, assessment and treatment of diffuse parenchymal lung disease in adults. Thorax 1999; 54:S1-S30. 
9 American Thoracic Society/European Respiratory Society International Multidisciplinary consensus classification of the idiopathic interstitial pneumonias. Am J Respir Crit Care Med 2002;165:277-304.

10 Raghu G, Mageto YN, Lockhart D, Schmidt RA, Wood DE, Godwin JD: The accuracy of clinical diagnosis of new onset idiopathic pulmonary fibrosis and other interstitial lung disease. Chest 1999;116:1168-1174.

11 Katzenstein AA, Myers JL: Idiopathic pulmonary fibrosis: Clinical relevance of pathologic classification. Am J Respir Crit Care Med 1998;157:1305-1315.

12 Cherian JM, Dahniya MH, Abul A, Behbehani N, Khadadah M, Al-Marzouk N: High resolution computed tomography in diffuse interstitial lung disease. Kuwait Med J 1999;31:2226.

13 Epler GR, Colby TV, McLoud TC, Carrington $\mathrm{CB}$, Gaensler EA: Bronchiolitis obliterans organizing pneumonia. N Engl J Med 1985;312: 152-158.

14 Colby TV: Pathologic aspects of bronchiolitis obliterans organizing pneumonia. Chest Suppl 1992; 102:38S-43S.

15 Coulter DB: Epidemiology of idiopathic pulmonary fibrosis. Semin Respir Med 1993;14: 181-196.
16 Crystal RG, Gadek JE, Ferrans VJ, Fulmer JD, Line BR, Hunninghake GW: Interstitial lung disease: Current concept of pathogenesis, staging and therapy. Am J Med 1981;70:542-568.

17 Memon A, Moody PM, Sugathan TN, ElGerges N, Al-Bustan M, Al-Shatti A, Al-Jazzaf $\mathrm{H}$ : Epidemiology of smoking among Kuwaiti adults: Prevalence characteristics and attitudes. Bull World Health Organ 2000;78: 1306-1315.

18 Hubbard R, Lewis S, Richards K, Johnston I, Britton J: Occupational exposure to metal or wood dust and aetiology of cryptogenic fibrosing alveolitis. Lancet 1996;347:284-289.

19 Baumgartner KB, Samet J, Stidley CA, Colby TV, Waldron JA: Cigarette smoking: A risk factor for idiopathic pulmonary fibrosis. Am J Respir Crit Care Med 1997;155:242-248.

20 Nagai S, Hoshino Y, Hayashi M, Ito I: Smoking related interstitial lung disease. Curr Opin Pulm Med 2000;6:415-419.

21 Grenier P, Valeyre D, Cluzel P, Brauner MW, Lenoir S, Chestang C: Chronic diffuse interstitial lung disease: Diagnostic value of chest radiography and high-resolution CT. Radiology 1991;179:123-132.

22 Roelandt M, Demedts M, Callebaut W, Coolen D, Slabbynck H, Bockaert J, Kips J, Brie J, Ulburghs M, DeBoeck K, Simons J, Van Meerbeeck K: Epidemiology of interstitial lung disease (ILD) in Flanders: Registration by pneumologists in 1992-1994. Acta Clin Belg 1995; 50:260-268.
23 American Thoracic Society: Idiopathic pulmonary fibrosis: Diagnosis and treatment international consensus statement. Am J Respir Crit Care Med 2000;161:646-664.

24 Coultas DB, Zumwalt RE, Black WC, Sobonya RE: The epidemiology of interstitial lung diseases. Am J Respir Crit Care Med 1994;150: 967-972.

25 Muller NL: Computed tomography in chronic interstitial lung disease. Radiol Clin North Am 1991;29:1085-1093.

26 Mathieson JR, Mayo JR, Staples CA, Muller NL: Chronic diffuse infiltrative lung disease: Comparison of diagnostic accuracy of CT and chest radiography. Radiology 1989;171:111116.

27 Muller NL, Miller RR: Computed tomography of chronic diffuse infiltrative lung disease. Part I. Am Rev Respir Dis 1990;142:1206-1215.

28 Muller NL, Miller RR: Computed tomography of chronic diffuse infiltrative lung disease. Part II. Am Rev Respir Dis 1990;142:1440-1448.

29 Johnston ID, Prescott RJ, Chalmers JC, Rudd RM: British Thoracic Society study of cryptogenic fibrosing alveolitis: Current presentation and initial management. Thorax 1997;52:3844. 